\title{
SEISMOTECTONIC CHARACTERISTICS OF THE AREA OF WESTERN ATTICA DERIVED FROM THE STUDY OF THE SEPTEMBER 7, 1999 ATHENS EARTHQUAKE AFTERSHOCK SEQUENCE.
}

\author{
N. VOULGARIS ${ }^{1}$, M. PIRLI ${ }^{1}$, P. PAPADIMITRIOU ${ }^{1}$, J. KASSARAS ${ }^{1}$ AND K. MAKROPOULOS ${ }^{1}$
}

\begin{abstract}
A detailed analysis of the aftershock sequence of the September 7, 1999 Athens earthquake was performed in order to define the fault planes activated during this sequence and study the tectonic regime of the area. Calculated fault plane solutions were verified by the composite solutions and the application of the principal parameters method. The combined results indicate a uniform tectonic status in the western part of the aftershock area, with normal faulting of WNW-ESE trend and an average dip of $60^{\prime} \mathrm{I}$ and a more complex one in the eastern part, where the azimuths of the activated fault planes vary and a transverse antithetic fault is also active. This variation could possibly imply a variation of the local stress field.
\end{abstract}

KEY WORDS: focal mechanisms; principal parameters method; eigenvalues; eigenvectors; Attica seismotectonic regime.

\section{INTRODUCTION}

A strong earthquake of magnitude $M_{s}=5.9$ occurred in the vicinity of Athens on September 7, 1999. The main shock, which was preceded by four foreshocks, took place at 11:56 GMT (14:56 local time). According to the Seismological Laboratory of the Department of Geophysics and Geothermics of the University of Athens the epicenter was located at $23^{\circ} \mathrm{E} 33.9^{\prime}$ and $38^{\circ} \mathrm{N} 06.3^{\prime}$, while the focal depth was estimated to be $8 \mathrm{~km}$. The focal mechanism of the main shock represents normal faulting with a fault plane trending $105^{\circ} \mathrm{N}$, and dipping $55^{\circ}$ (Papadimitriou et al, 2000; Papanastassiou et al, 2000; Tselentis and Zahradnik, 2000).

The main event was followed by a large number of aftershocks, which were recorded by a local, digital network of 8 portable stations (Voulgaris et al., 2000), installed in the epicentral area by the Athens University Seismological Laboratory the day after the main shock (figure 1), and remained in operation until December 1999. A total of 3261 of aftershocks were analyzed. The spatial distribution of the aftershock sequence (figure 1) displays a WNW-ESE trend and a dense concentration of aftershocks at the eastern part of the aftershock area. The focal depth distribution of the aftershocks, appears to be concentrated at a depth of 6-7 km, with only a few events exceeding the depth of $11 \mathrm{~km}$. Shallow events (depth $<3 \mathrm{~km}$ ) appear also to be rare. These observations can be verified from the four NNE-SSW cross sections of a width about $2 \mathrm{~km}$ (figure 2). In cross sections 1, 2, 3 the depth distribution of hypocenters indicates the geometry of the seismic fault plane. In cross section 4 , the image obtained is not as clear as in the former 3 and the existence of the transverse antithetic fault can be inferred.

\section{FAULT PLANE SOLUTIONS}

Initially, as a first step for the seismotectonic analysis of the September 7, 1999 aftershock sequence, 1051 events were selected and their focal mechanism solution was calculated using P-wave first motion polarities. The selection was based on the criteria of the number of available observations, which for the selected events was greater than 6 and sufficient azimuthal coverage. Most of the 1051, well constrained, focal mechanism solutions represent normal faulting (figure 3a), with only a small percentage of reverse and strike slip solutions. The solutions indicate a fault plane with geometry very similar to the one described by the spatial distribution of the aftershocks. However, rose diagrams of azimuth and dip orientation distribution, display a variety of fault plane orientations. As far as the dip orientation is concerned, a wide range of values appears, nevertheless, the largest concentration represents planes dipping westwards (figure $3 \mathrm{~b}$ ). A small number of eastwards dipping planes is also present.

1. University of Athens, Faculty of Geology, Department of Geophysics-Geothermics, Panepistimiopolis, 157 84, Zographou. 


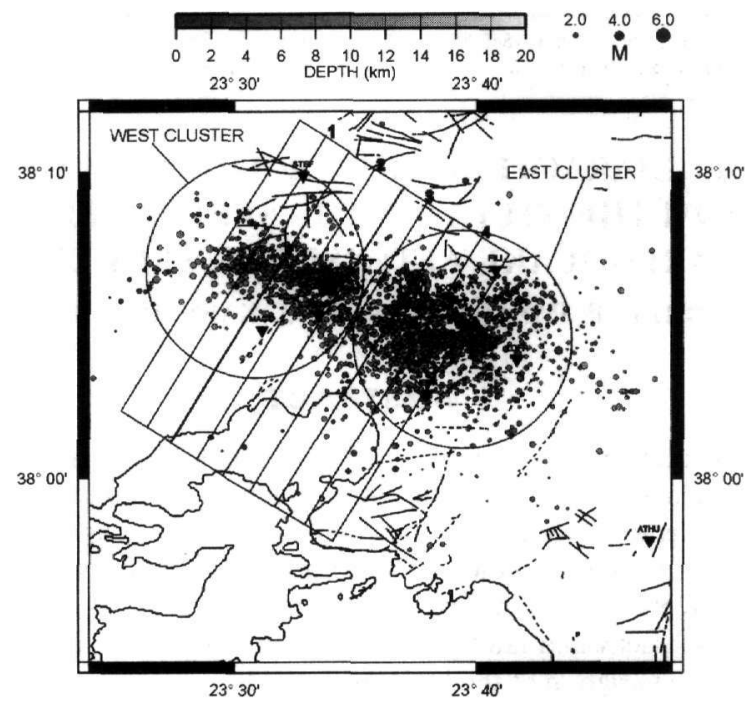

Fig.1: Schematic map of western Attica, showing the distribution of the aftershocks, the location of the epicenter of the main shock (star) and the locations of the seismological stations. The two circles correspond to the two sub-areas (see text). 1, 2, 3, 4: cross sections.

In addition, in order to verify the results obtained from the calculation of fault plane solutions for individual aftershocks and taking into account their spatial and temporal distribution, 20 composite solutions for selected groups of aftershocks were also calculated. These solutions when plotted on a tectonic map of the area (figure 4) showed good agreement with some of the known faults in the area. They all represent normal faulting, although variations regarding the azimuth of the nodal planes, especially at the eastern part, can be observed. These solutions also verified, up to a certain degree, the individual focal mechanism solutions, in the sense that more constrained solutions were provided. Nevertheless, the degree of validity of the obtained results was not entirely satisfying yet, creating the need for further verification, by applying an alternative methodology, independent of the number of first arrivals.
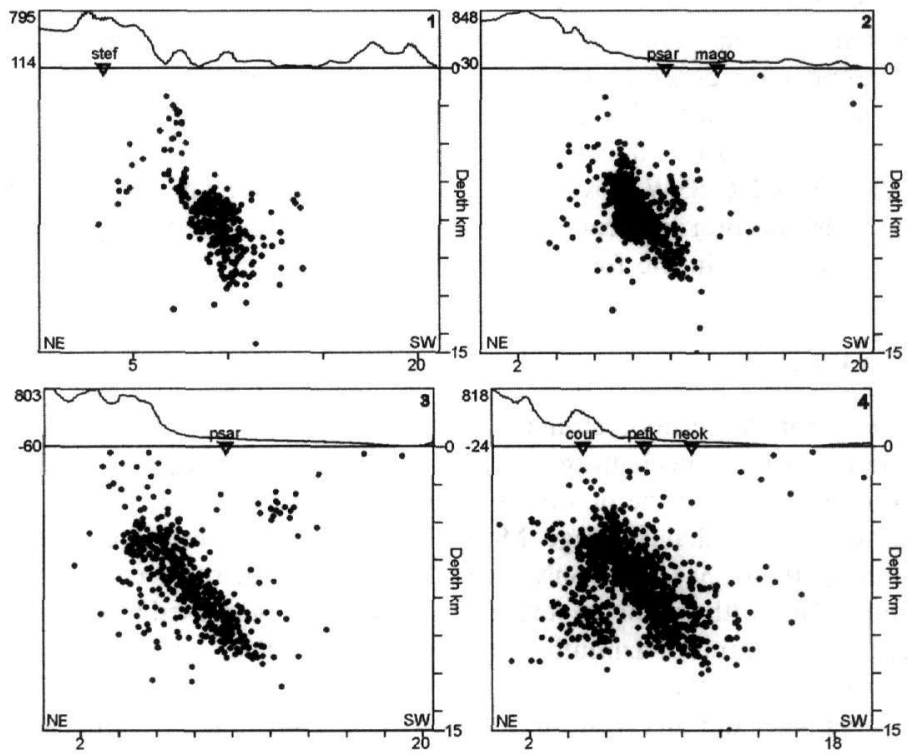

Fig.2: Cross sections with NNE-SSW trend and width of $2 \mathrm{~km}$, displaying the distribution of the aftershocks by depth. 

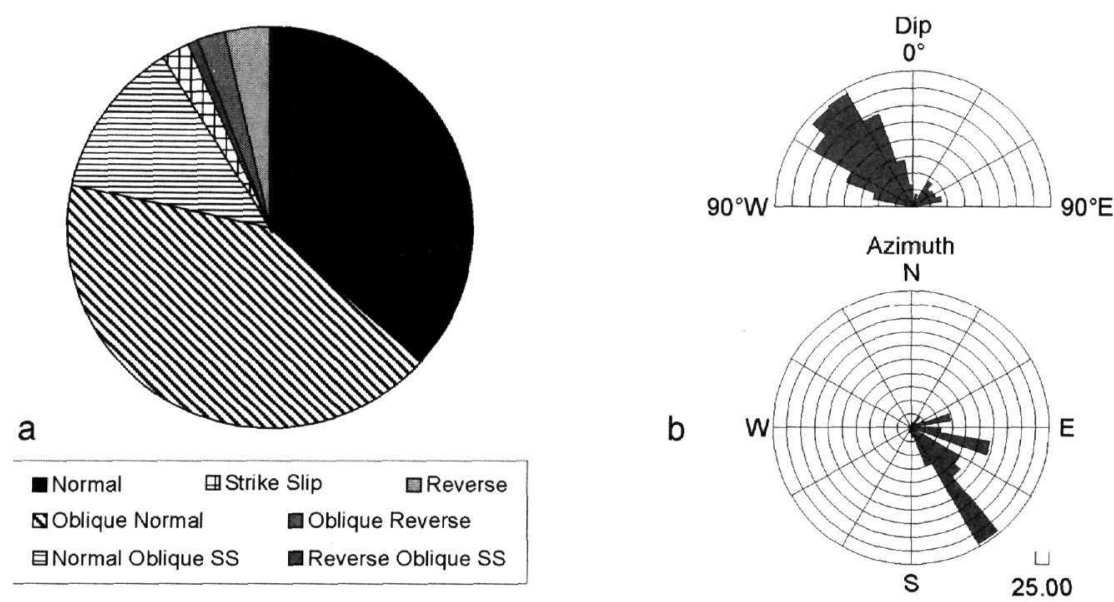

Fig.3: (a) Pie diagram of the types of focal mechanism solutions. (b) Rose diagrams for the azimuth and dip of the fault plane.

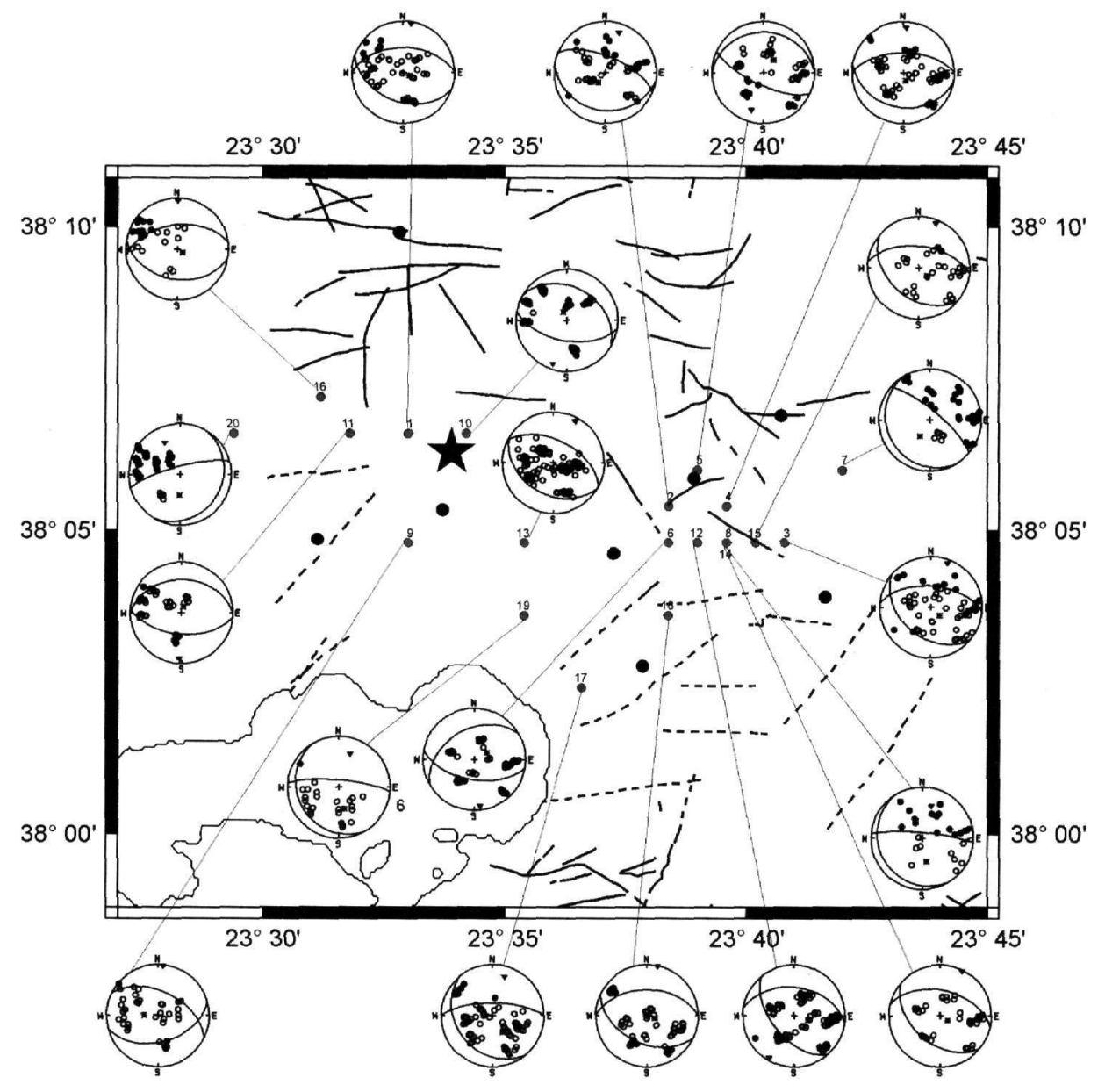

Fig.4: Schematic tectonic map of western Attica with the location of the main shock (star), the portable stations (black circles) and 20 composite focal mechanism solutions. 
Hence, the method of principal parameters (Ebbling and Michelini, 1986; Michelini and Bolt, 1986; Makropoulos et al, 1989) was selected in order to determine the orientation of the fault planes activated during the aftershock sequence of the September 7, 1999 earthquake.

\section{BRIEF DESCRIPTION OF THE PRINCIPAL PARAMETERS METHOD}

The main assumptions and the step-by-step procedure of the method may be summarized as follows.

An earthquake sequence is assumed to consist of a large number of faults within an active seismic volume embedded in the regional stress field. Each rupture causes a redistribution of the stress field and accumulation of stress on the boundary of the rupture surface and on adjacent faults, where the next earthquake is on the average expected to occur (Michelini and Bolt 1986). This progressive character of the model is supported by the observation that aftershocks are clustered in both space and time, suggesting that they are dependent of each other.

Therefore it is expected that the analysis of the spatial distribution of time successive events could get insight into the mechanism involved, by providing additional information about the time and space evolution of the rupturing system. Based on these assumptions and observations, the method consists of studying the spread, or variance-covariance matrix, of successive sets of temporally arranged events, within the aftershock sequence. This matrix may be regarded as defining the spatial ellipsoid, fitted through the foci, whose axes are the eigenvectors of the matrix, with lengths equal to the square roots of the eigenvalues. The comparison of the successive principal components is next attempted, while certain criteria for the flattening of the ellipsoid are taken into account in order to lead the comparison between successive coplanar ellipsoids.

The principal parameters of each group of coplanar ellipsoids are then averaged and projected on a lower hemisphere equal-area projection. Finally the planes perpendicular to the direction of the average of the smallest eigenvectors represent the planes that are the best fit of the foci.

More details about the step-by-step procedure can be found in Ebbling and Michelini (1986), Michelini and Bolt (1986), Makropoulos et al (1989).

\section{APPLICATION OF THE METHOD FOR THE ATHENS EARTHQUAKE AFTERSHOCK SEQUENCE}

Initially, during a testing phase, the method was applied to the whole aftershock area. Following the procedure described in Makropoulos et al (1989), a window width Q of 30 events was determined by testing for several values of $Q$ and constructing the diagram of the ratio of the intermediate and minimum eigenvalues $\left(\mathrm{T}_{2} / \mathrm{T}_{3}\right)$ as a function of $Q$.

Following the evaluation of initial results for the whole aftershock sequence (fig. 5a), which indicated variability in the distribution of the projections of the maximum and minimum eigenvectors, the aftershock area was divided in two sub-areas, a western and an eastern one. The division was performed, taking into account the spatial distribution of the aftershocks (figures 1 and 2), which seemed to imply the existence of two clusters as well as the results obtained by the calculation of first motion polarities fault plane solutions and the composite solutions.

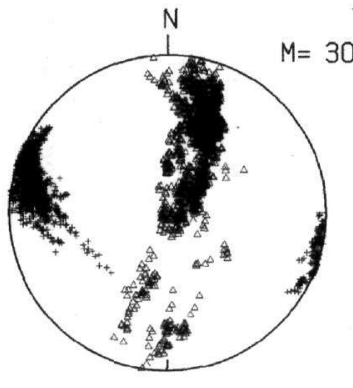

a

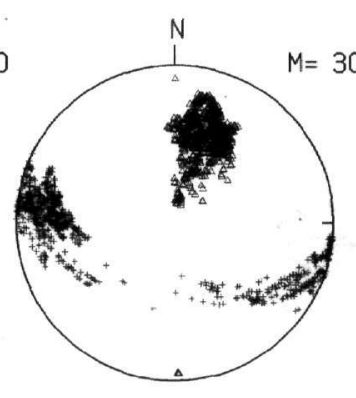

b

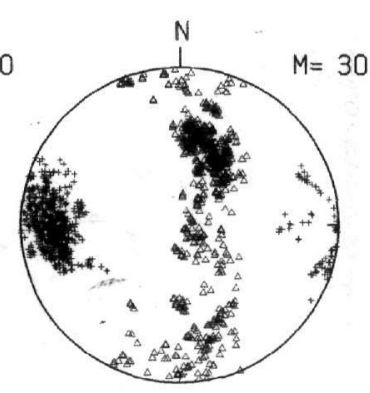

C

\section{Fig.5: Lower hemisphere equal-area projection of the maximum (+) and minimum (4) eigenvectors (a) for the whole aftershock area, (b) for the western sub-area and (c) for the eastern sub-area.}

Figure $5 \mathrm{~b}$ displays the projection of the maximum and minimum eigenvectors for the western sub-area, which is characterized by a highly clustered distribution of the projected vectors. In figure $5 \mathrm{c}$, on the other hand, which corresponds to the eastern sub-area, the projected values appear to be less concentrated occupying a large part of the projection area. 
The projections of the average of successive coplanar ellipsoids (figure 6a), which represent the results for the western sub-area, display a considerable degree of similarity. All of them corresponded to fault planes of azimuth between $110^{\circ} \pm 20^{\circ}$, with an average dip of $55^{\circ}$ to $60^{\circ}$. These parameters are in very good agreement with those calculated for the September 7, 1999 main shock as well as the individual and composite fault plane solutions calculated for events in this cluster.

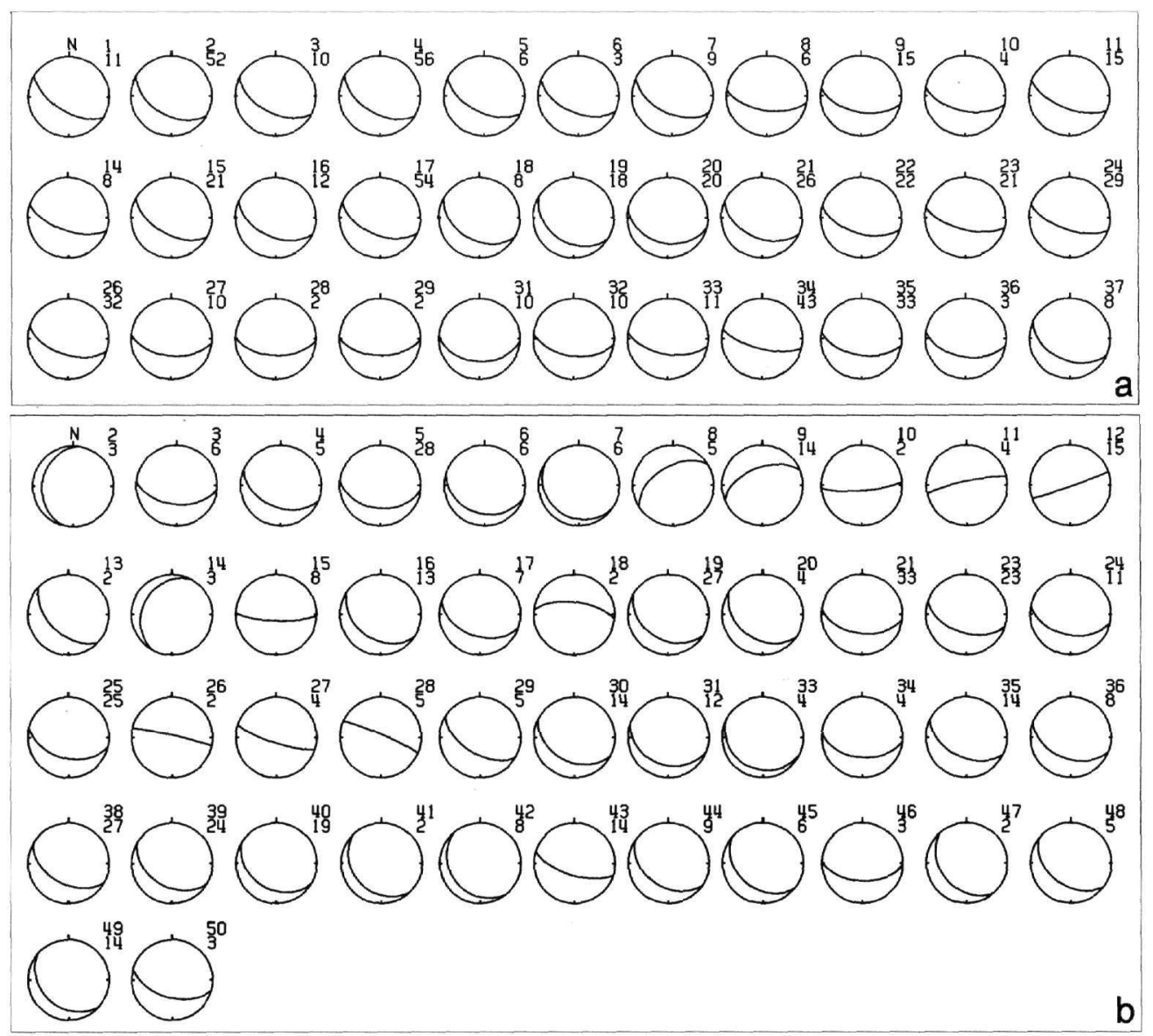

Fig.6: Lower hemisphere equal-area projection of the average of successive coplanar ellipsoids for the western (a) and eastern (b) sub-area. (a) Number 12,13,25 and 30 have been omitted as they consisted of one plane only. (b) Same for number 1, 22, 32 and 37.

In the eastern sub-area (figure $6 \mathrm{~b}$ ) the results indicate a greater variety of azimuths and dips for the activated fault planes, compared to the ones of the western sub-area. Moreover, apart from the solutions of similar type to that of the western cluster (e.g. solutions 3, 4, 5, 6, 7 etc), a second group of solutions characterized by different azimuth and dip direction (solutions $8,9,11,18,26,28$ ) is also evident supporting the activation of a transverse antithetic fault during the evolution of the aftershock sequence. Additional types of solutions (e.g. 2,14$)$ indicate that several secondary faults were also activated during the course of the aftershock sequence in the eastern part of the area.

\section{DISCUSSION AND CONCLUSIONS}

Statistical analysis performed on the results of the principal parameters method for both clusters (figure 7), weighted according to the number of successive coplanar ellipsoids of each solution (figure 6), confirmed the azimuth and dip uniformity of the western cluster, compared to the eastern cluster. The azimuth distribution rose diagrams for both clusters (figure $7 \mathrm{a}, \mathrm{d}$ ) indicate a small southwards rotation of the mean orientation of the fault plane in the eastern cluster. Moreover, in figure $7 \mathrm{~d}$ the activation of a transverse antithetic fault, trending 
$\mathrm{N} 60^{\circ} \mathrm{E}$, is confirmed. An increase of the mean dip of the calculated fault planes can be observed in the western cluster (figure $7 b, c)$, where the dip distribution appears to be more constrained.

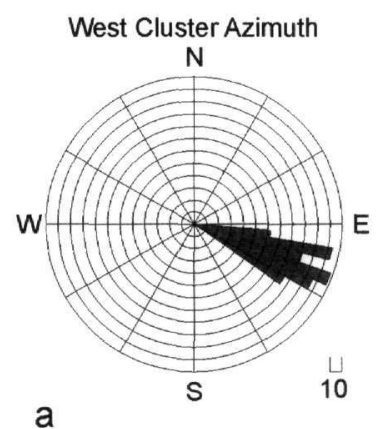

a

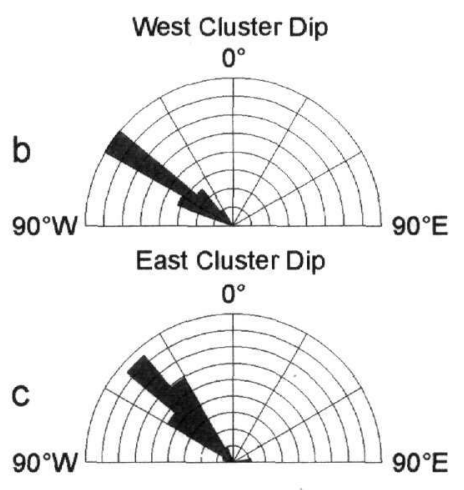

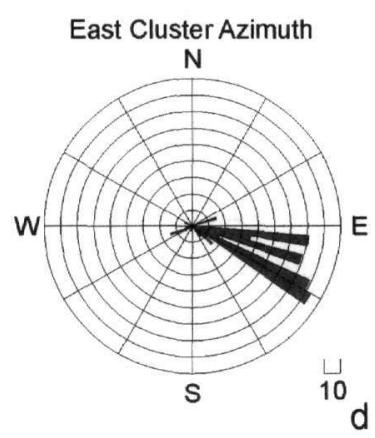

Fig.7: Rose diagrams for the weighted azimuth and dip distribution, according to the number of coplanar ellipsoids contained in each solution, of the suggested activated fault planes for the western and eastern subareas.

Evaluation of the reliability of the results obtained from the application of the principal parameters method for the September 7, $1999 \mathrm{M}=5.9$ aftershock sequence, as expressed by the number of coplanar ellipsoids per solution, indicates that the volume and quality of available data represent key factors for the success of the analysis (Ebbling and Michelini, 1986; Michelini and Bolt, 1986; Makropoulos et al, 1989). Furthermore, comparison with the solutions derived from the $\mathrm{P}$-wave first motion polarity method and the composite focal mechanisms confirms the accuracy and validity of these results.

Concerning the activated fault planes, the image obtained in the four cross sections of figure 2 , is also verified, as the easternmost of them fails to display a clearly shaped fault plane and the existence of a transverse antithetic fault is interrupting the linearity of the hypocenter distribution, observed in the former three cross sections.

These observations suggest a possible variation of the general E-W direction of the extensional seismotectonic regime in the area (Delibasis et al, 2000), which could be attributed to transpressional effects created by the presence of a tectonic boundary trending NE-SW to the east, in the vicinity of the convergence of Mount Parnitha with Mount Aegaleon (Mariolakos and Fountoulis, 2000). The former is expressed by the appearance of normal fault planes with uniform azimuth and dip, whereas the second is represented by the variety of activated fault planes and mechanism solution types.

\section{REFERENCES}

DELIBASIS N., PAPADIMITRIOU P., VOULGARIS N., KASSARAS I., 2000: The Parnitha fault: a possible relationship with other neighboring faults and causes of larger damages. Annales Geol. Des Pays Helleniques, 1e serie, tome XXXVIII, fasc. B, p. 41-50.

EBBLING C., MICHELINI A., 1986: A principal parameters analysis of aftershock sequences: applied to the 1977 Friuli, Italy, sequence. Ann. Geophys. 4,b,4, p. 473-480.

MAKROPOULOS K., TSELENTIS A., VOULGARIS N., DRAKOPOULOS J., 1989: Spatial and temporal evolution of the September 1986, Kalamata, Greece, aftershock sequence. Bull. Geol. Soc. Greece, vol. XXIII/3, p. 373-384.

MARIOLAKOS I., FOUNTOULIS I., 2000: The Athens earthquakes September 7, 1999: the neotectonic regime of the affected area. Annales Geol. Des Pays Helleniques, 1e serie, tome XXXVIII, fasc. B, p. 165-174.

MICHELINI A., BOLT B.A., 1986: Application of the principal parameters method to the 1983 Coalinga, California, aftershock sequence. Bull. of the Seismol. Soc. of America, vol. 76, No 2, p. 409-420.

PAPADIMITRIOU P., KAVIRIS G., VOULGARIS N., KASSARAS J. DELIBASIS N., MAKROPOULOS K., 2000: The September 7, 1999 Athens earthquake sequence recorded by the CORNET network: preliminary results of source parameters determination of the main shock. Annales Geol. Des Pays Helleniques, 1e serie, tome XXXVIII, fasc. B, p. 29-40. 
PAPANASTASSIOU D., STAVRAKAKIS G., DRAKATOS G., PAPADOPOUlOS G., 2000: The Athens, September 7, 1999, $M_{s}=5.9$, earthquake: first results on the focal properties of the main shock and the aftershock sequence. Annales Geol. Des Pays Helleniques, le serie, tome XXXVIII, fasc. B, p. 73-88.

TSELENTIS G.A., ZAHRADNIK J., 2000: Aftershock monitoring of the Athens earthquake of 7 September 1999. Seism. Res. Lett., vol. 71, p. 330-337.

VOULGARIS N., KASSARAS I., PAPADIMITRIOU P., DELIBASIS N., 2000: Preliminary results of the Athens September 7, 1999 aftershock sequence. Annales Geol. Des Pays Helleniques, 1e serie, tome XXXVIII, fasc. B, p. 51-62. 